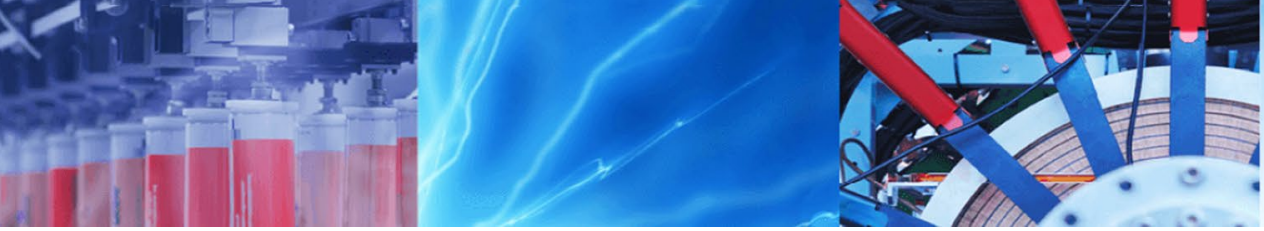

Case Study

\title{
Optimal laser welding process parameters and expected weld bead profile for P92 steel
}

\author{
G. Satyanarayana ${ }^{1} \cdot$ K. L. Narayana ${ }^{1} \cdot$ B. Nageswara Rao ${ }^{1}$
}

(c) Springer Nature Switzerland AG 2019

\begin{abstract}
P92 steel is classified as one of the creep strength enhanced ferritic steels, whose welding plays a crucial role in power industries. The best choice for such materials is the laser welding in open atmosphere with an inert gas shield. Compared to the frequently being used Taguchi based grey relational analysis, a simple and systematic approach known as the modified Taguchi design of experiments is utilized for P92 steel to obtain the optimized laser welding process parameters and the expected range of output responses. The complicated non-linear relationship between the laser welding process parameters (viz., laser power, welding speed and focal position) and the welding bead geometry (such as depth of penetration, weld width and heat affected zone width) is developed through empirical relations, which are validated by comparing with existing test results. Most of the test results are found to be within the expected range. From the ANOVA analysis the process parameter, viz. the focal position is found to have negligible variation on the overall mean value of the output responses and hence, the process designer can opt for any one the set levels of the focal position during welding operations.
\end{abstract}

Keywords Depth of penetration · Focal position · Heat affected zone - Laser power · Laser welding · P92 steel · Taguchi approach $\cdot$ Weld width $\cdot$ Welding speed

\section{Introduction}

Development of high efficiency systems with low emission is a continuous process to address economical and environmental issues of thermal power plants. Increasing of thermal efficiency minimizes the fuel consumption and emissions of environmentally damaging gases. In order to enhance the thermal efficiency, there is a need for increasing the operating temperatures and pressures, which demands use of creep strength enhanced ferritic (CSEF) steels for constructing parts of advanced power plants [1-3]. The P91 and P92 martensitic steels are prominent for high-temperature application. P92 steels are modified version of P91 steels. They are obtained by adding tungsten (1.5-2.0 wt\%) as well as boron (0.001-0.002 wt\%) and reducing molybdenum (to $0.5 \mathrm{wt} \%$ ). Presence of tungsten reduces coarsening rate of $\mathrm{M}_{23} \mathrm{C}_{6}$ precipitates and offers solid solution strengthening. $\mathrm{P} 92$ steels have high thermal conductivity, low coefficient of thermal expansion, resistance to stress corrosion cracking and oxidation. P91 and P92 steels can be welded by any fusion welding processes. However, weldments of P92 steels are failed under creep in the fine grain region of $\mathrm{HAZ}$ at elevated temperatures [4-6]. Utilization of laser welding makes easy shielding of molten pool and avoids hydrogen induced cracking. Also, reduces formation of soft inter-critical zone and deleterious phase $[7,8]$. Laser welding is thus a promising process to perform in the open atmosphere with inert gas shielding. For achieving the quality weld, there is a need for tracing the optimized welding process parameters to

B. Nageswara Rao, bnrao52@rediffmail.com; G. Satyanarayana, gotetisatya@yahoo.co.in; K. L. Narayana, drkln@kluniversity.in | 'Department of Mechanical Engineering, Koneru Lakshmaiah Education Foundation, Deemed to be University, Green Fields, Vaddeswaram, Guntur 522 502, India. 
have deep and narrow penetration, low weld bead width and narrow heat effected zone (HAZ). One has to examine the adequacy of existing simple theory or develop a suitable algorithm for obtaining a solution for such nonlinear optimization problem.

Selection of an orthogonal array to conduct few experiments, acquiring complete information and confirmation of the identified optimum input process parameters through additional testing (if necessary) is a standard practice in the Taguchi approach [9]. Taguchi method is a systematic statistical approach, which has been successfully utilized in solving several engineering/industrial optimization problems such as minimization of drilling induced delamination type damages in composite structures, investigations on the significance of input parameters in the stage and satellite separation processes during flight of space launch vehicles, influence of parameters on the performance of chevron type plate heat exchangers and the selection of input process parameters for achieving optimum output responses [10-21].

Shanmugarajan et al. [22] have made an interesting experimental study to optimize the laser welding process for $\mathrm{P} 92$ steel by using the signal-to-noise $(\mathrm{S} / \mathrm{N})$ ratio transformation and the Taguchi based grey relational analysis (GRA). The concept of $\mathrm{S} / \mathrm{N}$ ratio transformation introduced by Taguchi is to account the scatter in the output response of repeated tests for each test run in the orthogonal array and provide a single value to perform analysis of variance (ANOVA) and examine the significance of the input process variables. Many researchers have utilized the $S / N$ ratio transformation while obtaining the optimal solution of several manufacturing processes such as machining of a hardened steel cylindrical work-piece $[23,24]$ and commercial mild steel [25]; Dry end milling operation of Al-6063 [26]; AISI 1020 mild steel bar in turning operation [27]; high-speed cold rolling-beating processing parameters [28]; electrochemical machining for $\mathrm{Al} / \mathrm{B}_{4} \mathrm{C}$ composites [29, 30]; EDM for Incoloy 600 [31]; WEDM for AISI H13 steel [32], stainless steel [33] and titanium alloy $[34,35]$; MIG welding for AM-40 aluminium alloy [36]; and friction stir welding process of aluminium alloy [37-39]. However, the additive law [9] estimates the deterministic output response from the mean values of the ANOVA table and unable to provide the expected range of the output response. Taguchi method is adequate to identify the optimum process parameters for a single response characteristic. In the case of multiple responses having dissimilar quality characteristics, multi-objective optimization using grey relational analysis (GRA) is being utilized extensively [40-45]. There is a possibility to represent functionally the dissimilar quality characteristics of multiple responses into a single response characteristic after non-dimensioning them. This single response characteristic can be used easily to identify the optimum process parameters adopting the Taguchi approach. There is a need to specify the expected range of optimum output responses by identifying a set of input process variables.

Industries expect simple, reliable and easy to implement procedures for solving optimization problems. Several researchers [46] are on use of many other algorithms (such as grey relational analysis (GRA) [40-45], genetic algorithm (GA) $[47,48]$, teacher learning base algorithm (TLBA) [49], response surface methodology (RSM) [50], particle swarm optimization (PSO) [51], etc.) without highlighting drawbacks in existing theories. When no repetition of experiments planned, the application of $\mathrm{S} / \mathrm{N}$ ratio transformation to the output responses will not provide any improvement in optimal solutions. Many of the referred articles present the $\%$ contribution of process parameters without discussing their significance on output responses as well as in the obtained optimal solutions. In fact, multi-objective optimization is not a straightforward approach and Taguchi approach is well proven for single-objective optimization problems. Being simple and reliable, extension of Taguchi approach to multi-objective optimization problems is desirable. This paper demonstrates the simplicity and the adequacy of Taguchi approach to handle multi-objective optimization problems related to laser welding process for P92 steel. It follows the modified Taguchi method [19] in finding the expected range of the output responses and a simple multi-objective optimization technique $[14,15]$ when compared to the Taguchi based grey relational analysis of [22]. Empirical relations for the output responses are developed in terms of input process variables and validated with existing test results. The test results are found to be within the expected range. This study recommends the process designer to set any one of the set levels for insignificant process parameters.

\section{Test data acquisition}

Laser welding process can be performed in the open atmosphere with inert gas shielding. The quality weld can be expected through optimum welding process parameters which yield deep and narrow penetration, low weld bead width and narrow heat effected zone (HAZ). Shanmugarajan et al. [22] have performed experiments to specify optimum laser welding process parameters for P92 steel by using the signal-to-noise $(\mathrm{S} / \mathrm{N})$ ratio transformation and the Taguchi based grey relational analysis (GRA). The P92 steel plates have rectangular geometric shape and the dimensions are $200 \mathrm{~mm}$ of length, $150 \mathrm{~mm}$ of width and $8 \mathrm{~mm}$ of thickness. Table 1 gives the chemical composition (wt\%) of the P92 steel. 
Table 1 The chemical composition (wt\%) of the P92 steel

\begin{tabular}{ll}
\hline Elements & Weight (\%) \\
\hline $\mathrm{C}$ & 0.125 \\
$\mathrm{Si}$ & 0.244 \\
$\mathrm{Mn}$ & 0.42 \\
$\mathrm{P}$ & 0.02 \\
$\mathrm{~S}$ & $<0.01$ \\
$\mathrm{Cr}$ & 8.834 \\
$\mathrm{Mo}$ & 0.302 \\
$\mathrm{Ni}$ & 0.395 \\
$\mathrm{~V}$ & 0.184 \\
$\mathrm{Nb}$ & 0.076 \\
$\mathrm{~W}$ & 1.724 \\
$\mathrm{~B}$ & 0.001 \\
$\mathrm{Fe}$ & Balance \\
\hline
\end{tabular}

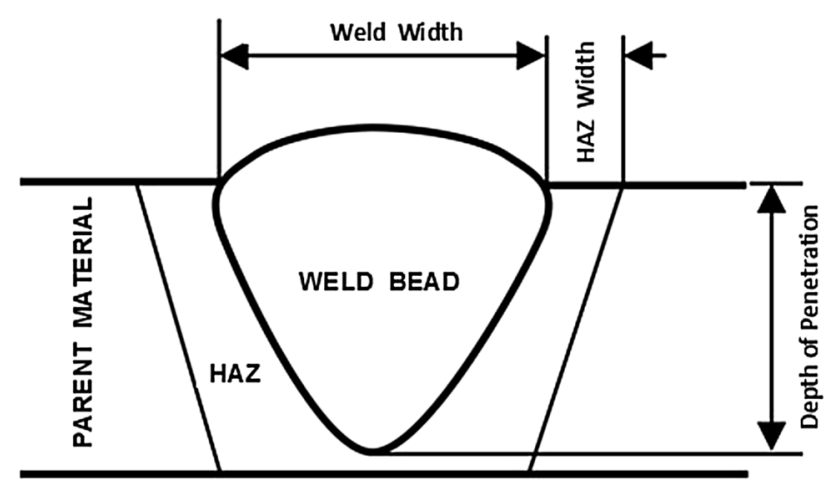

Fig. 1 Schematic representation of bead geometry

Taguchi's $L_{9}$ orthogonal array is adopted by assigning three levels for the three laser welding process parameters (viz., laser power, welding speed and focal position). Bead on plate (BOP) trials are made using a $3.5 \mathrm{~kW}$ diffusion cooled slab $\mathrm{CO}_{2}$ laser. Figure 1 shows the schematic representation of bead geometry. The optimum laser welding process parameters are identified for achieving maximum depth of penetration and narrow weld bead width. To avoid the sequential error the welding experimental tests are performed twice in a random manner. To examine the microstructures, welds are cut in the transverse direction. Later on, they are polished and etched using Villella's reagent. Leica Stereo microscope having built-in software is used for taking microstructures and subsequently measured the bead geometry.

\section{Development of empirical relations based on the Taguchi's design of experiments}

Taguchi method is a systematic statistical approach, which demands few experiments and provides complete information for the full factorial design of experiments. As per the Taguchi design of experiments, the relation between the number of experiments ( $\mathrm{N}_{\text {Taguchi }}$ ), and the factors or input parameters $\left(n_{p}\right)$ with their assigned levels $\left(n_{l}\right)$ is

$$
\begin{aligned}
\mathrm{N}_{\text {Taguchi }} & =1+(\text { Number of factors }) \times(\text { Number of Levels }-1) \\
& =1+n_{p} \times\left(n_{l}-1\right)
\end{aligned}
$$

For $n_{p}=4$ and $n_{l}=3, n_{l}^{n_{p}}=3^{4}=81$ tests are to be conducted for full factorial design of experiments, whereas Eq. (1) indicates only $\mathrm{N}_{\text {Taguchi }}=9$ experiments and hence Taguchi's $L_{9}$ orthogonal array will be more appropriate.

\subsection{Analysis of variance (ANOVA)}

The design of experiments in [22] involves 3 input process variables such as laser power, welding speed and focal position assigning 3 levels for each these independent variables in the selected $L_{9}$ orthogonal array. For easy of reference, the 3 input process parameters (viz., laser power, welding speed and focal position) are designated by $A, B$ and $C$ respectively. The recorded output responses, viz., weld width, depth of penetration, and heat affected zone (HAZ) width are designated by the symbols $\alpha, \beta$ and $\gamma$ respectively. Levels of laser welding process parameters and the performance output responses as per $L_{9}$ orthogonal array are presented in Table 2.

When $N_{\text {Taguchi }}=9$ and number of levels $n_{l}=3$, Eq. (1) gives four number of factors that can be accommodated. As in [14], a fictitious factor (fourth factor) D is also introduced in Table 2. The sensitiveness of the change in the level of setting is examined by determining the sum of the squares (SOS) of deviation of each of the mean value from the overall mean. Percentage contribution is obtained by dividing the sum of the squares of each process parameter with the total sum of the squares. Analysis of variance (ANOVA) is thus performed to identify the optimum laser welding process parameters for obtaining maximum depth of penetration and minimum weld width. Regarding the individual contribution of input parameters on the output responses, it is noted from the ANOVA results of Table 3 that welding speed (B) has an immense effect on the depth of penetration with $88.7 \%$ contribution and other parameters like laser power (A) and focal position (C) on the depth of penetration are 8.6 and $2.2 \%$ respectively. Welding speed (B) has $85.8 \%$ contribution on the top bead width and other parameters like laser power (A) and focal position (C) on the top bead width are 12.8 and $0.6 \%$ respectively.

It should be noted that sum of the \% Contributions including the fictitious parameter (D) in the ANOVA results of Table 3 for the three output responses is 100 . Hence, Error (\%) with inclusion of the fictitious parameter (D) is zero, whereas with exclusion of $D$, the Error (\%) is equal 
Table 2 Performance output responses, viz., top bead width $(\alpha)$, depth of penetration $(\beta)$ and heat affected zone $(\gamma)$ for the assigned laser weld process parameters as per $\mathrm{L}_{9}$ orthogonal array

\begin{tabular}{|c|c|c|c|c|c|c|c|}
\hline \multicolumn{2}{|c|}{ Control factors (input parameters) } & \multicolumn{2}{|c|}{ Designated factor } & Level-1 & \multicolumn{2}{|c|}{ Level-2 } & Level-3 \\
\hline \multicolumn{8}{|c|}{ Assignment levels of laser weld process parameters } \\
\hline \multicolumn{2}{|c|}{ Power $(\mathrm{kW})$} & \multicolumn{2}{|c|}{ A } & 2.5 & \multicolumn{2}{|c|}{3} & 3.5 \\
\hline Speed (m/min) & & \multicolumn{2}{|c|}{ B } & 1 & \multicolumn{2}{|c|}{3} & 5 \\
\hline Focus (mm) & & \multicolumn{2}{|c|}{$\mathrm{C}$} & 0 & \multicolumn{2}{|c|}{-2} & -4 \\
\hline Fictitious & & \multicolumn{2}{|c|}{$\mathrm{D}$} & $d_{1}$ & \multicolumn{2}{|c|}{$d_{2}$} & $d_{3}$ \\
\hline \multirow[t]{2}{*}{ Test run } & \multicolumn{4}{|c|}{ Levels of input parameters } & \multicolumn{3}{|c|}{ Output responses [22] } \\
\hline & A & B & $\mathrm{C}$ & $\mathrm{D}$ & $\alpha(\mu \mathrm{m})$ & $\beta(\mu \mathrm{m})$ & $\gamma(\mu \mathrm{m})$ \\
\hline \multicolumn{8}{|l|}{ Output responses } \\
\hline 1 & 1 & 1 & 1 & 1 & 2156 & 5310 & 1257.4 \\
\hline 2 & 1 & 2 & 2 & 2 & 1480.9 & 3945.7 & 628.8 \\
\hline 3 & 1 & 3 & 3 & 3 & 1310 & 2017.2 & 382.4 \\
\hline 4 & 2 & 1 & 2 & 3 & 2367.2 & 6089.5 & 1287 \\
\hline 5 & 2 & 2 & 3 & 1 & 1493.2 & 4038.2 & 786.4 \\
\hline 6 & 2 & 3 & 1 & 2 & 1290 & 3028.2 & 563.6 \\
\hline 7 & 3 & 1 & 3 & 2 & 2730.3 & 5967.3 & 1466.4 \\
\hline 8 & 3 & 2 & 1 & 3 & 1810.3 & 5046.8 & 780.4 \\
\hline 9 & 3 & 3 & 2 & 1 & 1581.3 & 3085.3 & 735.8 \\
\hline Overall mean & & & & & 1802.1 & 4280.9 & 876.5 \\
\hline
\end{tabular}

Table 3 Analysis of variance (ANOVA) on the output responses of Table 2

\begin{tabular}{lccccc}
\hline Parameters & 1-Mean & 2-Mean & 3-Mean & Sum of squares & \% Contribution \\
\hline \multicolumn{2}{l}{ Top bead width, $\alpha(\mu \mathrm{m})$} & & & & \\
A & 1649 & 1716.8 & 2040.6 & 262,872 & 12.8 \\
B & 2417.8 & 1594.8 & 1393.8 & $1,766,511$ & 85.8 \\
C & 1752.1 & 1809.8 & 1844.5 & 13,071 & 0.6 \\
D & 1743.5 & 1833.7 & 1829.2 & 15,502 & 0.8 \\
Depth of penetration, $\beta(\mu \mathrm{m})$ & & & & \\
A & 3757.6 & 4385.3 & 4699.8 & $1,380,554$ & 8.6 \\
B & 5788.9 & 4343.6 & 2710.2 & $14,235,256$ & 88.7 \\
C & 4461.7 & 4373.5 & 4007.6 & 347,887 & 2.2 \\
D & 4144.5 & 4313.7 & 4384.5 & 91,248 & 0.5 \\
Heat affected zone & $\gamma(\mu \mathrm{m})$ & & & & \\
A & 756.2 & 879 & 994.2 & 84,995 & 7.7 \\
B & 1336.9 & 731.9 & 560.6 & 998,131 & 90.6 \\
C & 867.1 & 883.9 & 878.4 & 437 & 0.0 \\
D & 926.5 & 886.3 & 816.6 & 18,560 & 1.7 \\
\hline
\end{tabular}

to that of the \% Contribution of D. This may be the reason why the additive law (2) predicts the output responses close to the test results with inclusion of the fictitious parameter (D) with no additional experimentation by adding additional column in the Taguchi's $\mathrm{L}_{9}$ orthogonal array.

\subsection{Expected range of the output response}

The expected range of the output responses is preferable to account the scatter in repeated experiments. It is possible to establish empirical relations for the output responses in terms of input variables. From the ANOVA results of Table 3 , the estimated output responses viz., top bead width $(\alpha)$, depth of penetration ( $\beta$ ) and heat affected zone $(\gamma)$ for the assigned levels of input parameters in Table 2 are presented in Table 4. The additive law [9] in Eq. (2) is used for estimation of the output response $(\phi)$ for each test run.

$\bar{\phi}=\phi_{\text {mean }}+\sum_{i=1}^{n_{p}}\left(\phi_{i}-\phi_{\text {mean }}\right)$ 
Here $\bar{\phi}$ is the estimated output response; $\phi_{\text {mean }}$ is the overall mean of $\phi ; \phi_{i}$ is the mean of $\phi$ at the specified level for the process parameters $(i)$; and $n_{p}$ is the number of process parameters. The estimated output responses in Table 4 for the 9 test runs are found to be reasonably in good agreement with test results. It should be noted that $n_{p}=3$ in Eq. (2) corresponds to the estimates of the output response with exclusion of fictitious parameter (D), whereas $n_{p}=4$ corresponds to the estimates of the output response with inclusion of fictitious parameter (D). With inclusion of fictitious parameter (D), the estimates of output responses in Table 4 are very close to the test results. Considering the levels of lowest and highest mean values of $\phi$ for the fictitious parameter (D) the expected range for the output responses is arrived. The test results in Table 4 are found to be within the expected range of the output responses. Taguchi design of experiments suggests only nine experiments for the present case study having three process parameters with three levels. The additive law [9] of Taguchi approach given in Eq. (2) provides the estimates of output responses for all possible 27 combinations of input variables. Table 5 gives estimates of the output responses for the full factorial design of experiments useful in examining the influence of insignificant process parameters on the variation of output responses.

Since the percentage contribution of focal position (C) is negligibly small, empirical relations are developed from the mean values for top bead width $(\alpha)$, depth of penetration $(\beta)$ and heat affected zone $(\gamma)$ in terms of the input parameters viz., laser power $(A)$ and welding power $(B)$ as

$\alpha=512 A^{2}+77.8 B^{2}-2680 A-723 B+6410$
Table 4 Estimates of the top bead width, $\alpha(\mu \mathrm{m})$, depth of penetration, $\beta(\mu \mathrm{m})$, and width of the heat affected zone, $\gamma$ $(\mu \mathrm{m})$, and comparison with test data [22]

\begin{tabular}{|c|c|c|c|c|c|c|c|c|c|c|}
\hline \multirow[t]{2}{*}{ Test Run } & \multicolumn{4}{|c|}{$\begin{array}{l}\text { Levels of input } \\
\text { parameters }\end{array}$} & \multirow[t]{2}{*}{ Test [22] } & \multicolumn{3}{|c|}{ Estimate Eq. (2) } & \multicolumn{2}{|c|}{ Expected range } \\
\hline & A & B & C & $\mathrm{D}$ & & $n_{p}=3$ & R.E. (\%) & $n_{p}=4$ & Lower bound & Upper bound \\
\hline \multicolumn{11}{|c|}{ Top bead width, $\alpha(\mu \mathrm{m})$} \\
\hline 1 & 1 & 1 & 1 & 1 & 2156 & 2214.6 & -2.7 & 2156 & 2156 & 2246.2 \\
\hline 2 & 1 & 2 & 2 & 2 & 1480.9 & 1449.3 & 2.1 & 1480.9 & 1390.7 & 1480.9 \\
\hline 3 & 1 & 3 & 3 & 3 & 1310 & 1283 & 2.1 & 1310 & 1224.3 & 1314.6 \\
\hline 4 & 2 & 1 & 2 & 3 & 2367.2 & 2340.2 & 1.1 & 2367.2 & 2281.5 & 2371.8 \\
\hline 5 & 2 & 2 & 3 & 1 & 1493.2 & 1551.8 & -3.9 & 1493.2 & 1493.2 & 1583.4 \\
\hline 6 & 2 & 3 & 1 & 2 & 1290 & 1258.4 & 2.4 & 1290 & 1199.8 & 1290 \\
\hline 7 & 3 & 1 & 3 & 2 & 2730.3 & 2698.7 & 1.2 & 2730.3 & 2640.1 & 2730.3 \\
\hline 8 & 3 & 2 & 1 & 3 & 1810.3 & 1783.3 & 1.5 & 1810.3 & 1724.6 & 1814.9 \\
\hline 9 & 3 & 3 & 2 & 1 & 1581.3 & 1639.9 & -3.7 & 1581.3 & 1581.3 & 1671.5 \\
\hline \multicolumn{11}{|c|}{ Depth of penetration, $\beta(\mu \mathrm{m})$} \\
\hline 1 & 1 & 1 & 1 & 1 & 5310 & 5446.4 & -2.6 & 5310 & 5310 & 5550 \\
\hline 2 & 1 & 2 & 2 & 2 & 3945.7 & 3912.9 & 0.8 & 3945.7 & 3776.5 & 4016.5 \\
\hline 3 & 1 & 3 & 3 & 3 & 2017.2 & 1913.6 & 5.1 & 2017.2 & 1777.2 & 2017.2 \\
\hline 4 & 2 & 1 & 2 & 3 & 6089.5 & 5985.9 & 1.7 & 6089.5 & 5849.5 & 6089.5 \\
\hline 5 & 2 & 2 & 3 & 1 & 4038.2 & 4174.6 & -3.4 & 4038.2 & 4038.2 & 4278.2 \\
\hline 6 & 2 & 3 & 1 & 2 & 3028.2 & 2995.4 & 1.1 & 3028.2 & 2859 & 3099 \\
\hline 7 & 3 & 1 & 3 & 2 & 5967.3 & 5934.5 & 0.5 & 5967.3 & 5798.1 & 6038.1 \\
\hline 8 & 3 & 2 & 1 & 3 & 5046.8 & 4943.2 & 2.1 & 5046.8 & 4806.8 & 5046.8 \\
\hline 9 & 3 & 3 & 2 & 1 & 3085.3 & 3221.7 & -4.4 & 3085.3 & 3085.3 & 3325.3 \\
\hline \multicolumn{11}{|c|}{ Heat affected zone, $\gamma(\mu \mathrm{m})$} \\
\hline 1 & 1 & 1 & 1 & 1 & 1257.4 & 1207.3 & 4.0 & 1257.4 & 1147.5 & 1257 \\
\hline 2 & 1 & 2 & 2 & 2 & 628.8 & 619 & 1.6 & 628.8 & 559.1 & 669.1 \\
\hline 3 & 1 & 3 & 3 & 3 & 382.4 & 442.3 & -15.7 & 382.4 & 382.4 & 492.3 \\
\hline 4 & 2 & 1 & 2 & 3 & 1287 & 1346.9 & -4.7 & 1287 & 1287 & 1397 \\
\hline 5 & 2 & 2 & 3 & 1 & 786.4 & 736.33 & 6.4 & 786.4 & 676.5 & 786.4 \\
\hline 6 & 2 & 3 & 1 & 2 & 563.6 & 553.8 & 1.7 & 563.6 & 493.9 & 603.9 \\
\hline 7 & 3 & 1 & 3 & 2 & 1466.4 & 1456.6 & 0.7 & 1466.4 & 1396.7 & 1507 \\
\hline 8 & 3 & 2 & 1 & 3 & 780.4 & 840.3 & -7.7 & 780.4 & 780.4 & 890.3 \\
\hline 9 & 3 & 3 & 2 & 1 & 735.8 & 685.73 & 6.8 & 735.8 & 625.9 & 735.8 \\
\hline
\end{tabular}


Table 5 Estimates of output responses for the full factorial design of experiments

\begin{tabular}{|c|c|c|c|c|c|c|c|c|c|}
\hline \multirow[t]{2}{*}{ S. No. } & \multicolumn{3}{|c|}{$\begin{array}{l}\text { Levels of input } \\
\text { parameters }\end{array}$} & \multicolumn{2}{|c|}{ Top bead width, $\alpha$ ( $\mu \mathrm{m})$} & \multicolumn{2}{|c|}{ Depth of penetration, $\beta(\mu \mathrm{m})$} & \multicolumn{2}{|c|}{ Heat affected zone, $\gamma(\mu \mathrm{m})$} \\
\hline & A & B & $C$ & Lower bound & Upper bound & Lower bound & Upper bound & Lower bound & Upper bound \\
\hline 1 & 1 & 1 & 1 & 2156 & 2246.2 & 5310 & 5550 & 1147.5 & 1257 \\
\hline 2 & 1 & 1 & 2 & 2213.7 & 2303.9 & 5221.8 & 5461.8 & 1164.2 & 1274 \\
\hline 3 & 1 & 1 & 3 & 2248.4 & 2338.6 & 4855.9 & 5095.9 & 1158.7 & 1269 \\
\hline 4 & 1 & 2 & 1 & 1333 & 1423.2 & 3864.6 & 4104.6 & 542.4 & 652.3 \\
\hline 5 & 1 & 2 & 2 & 1390.7 & 1480.9 & 3776.5 & 4016.5 & 559.13 & 669.1 \\
\hline 6 & 1 & 2 & 3 & 1425.4 & 1515.6 & 3410.5 & 3650.5 & 553.67 & 663.6 \\
\hline 7 & 1 & 3 & 1 & 1131.9 & 1222.2 & 2231.3 & 2471.3 & 371.13 & 481.1 \\
\hline 8 & 1 & 3 & 2 & 1189.6 & 1279.9 & 2143.1 & 2383.1 & 387.87 & 497.8 \\
\hline 9 & 1 & 3 & 3 & 1224.3 & 1314.6 & 1777.2 & 2017.2 & 382.4 & 492.3 \\
\hline 10 & 2 & 1 & 1 & 2223.8 & 2314.1 & 5937.7 & 6177.7 & 1270.3 & 1380 \\
\hline 11 & 2 & 1 & 2 & 2281.5 & 2371.8 & 5849.5 & 6089.5 & 1287 & 1397 \\
\hline 12 & 2 & 1 & 3 & 2316.2 & 2406.5 & 5483.6 & 5723.6 & 1281.5 & 1391 \\
\hline 13 & 2 & 2 & 1 & 1400.8 & 1491 & 4492.3 & 4732.3 & 665.2 & 775.1 \\
\hline 14 & 2 & 2 & 2 & 1458.5 & 1548.7 & 4404.1 & 4644.1 & 681.93 & 791.9 \\
\hline 15 & 2 & 2 & 3 & 1493.2 & 1583.4 & 4038.2 & 4278.2 & 676.47 & 786.4 \\
\hline 16 & 2 & 3 & 1 & 1199.8 & 1290 & 2859 & 3099 & 493.93 & 603.9 \\
\hline 17 & 2 & 3 & 2 & 1257.5 & 1347.7 & 2770.8 & 3010.8 & 510.67 & 620.6 \\
\hline 18 & 2 & 3 & 3 & 1292.2 & 1382.4 & 2404.9 & 2644.9 & 505.2 & 615.1 \\
\hline 19 & 3 & 1 & 1 & 2547.7 & 2637.9 & 6252.2 & 6492.2 & 1385.5 & 1495 \\
\hline 20 & 3 & 1 & 2 & 2605.4 & 2695.6 & 6164 & 6404 & 1402.2 & 1512 \\
\hline 21 & 3 & 1 & 3 & 2640.1 & 2730.3 & 5798.1 & 6038.1 & 1396.7 & 1507 \\
\hline 22 & 3 & 2 & 1 & 1724.6 & 1814.9 & 4806.8 & 5046.8 & 780.4 & 890.3 \\
\hline 23 & 3 & 2 & 2 & 1782.3 & 1872.6 & 4718.6 & 4958.6 & 797.13 & 907.1 \\
\hline 24 & 3 & 2 & 3 & 1817 & 1907.3 & 4352.7 & 4592.7 & 791.67 & 901.6 \\
\hline 25 & 3 & 3 & 1 & 1523.6 & 1613.8 & 3173.5 & 3413.5 & 609.13 & 719.1 \\
\hline 26 & 3 & 3 & 2 & 1581.3 & 1671.5 & 3085.3 & 3325.3 & 625.87 & 735.8 \\
\hline 27 & 3 & 3 & 3 & 1616 & 1706.2 & 2719.4 & 2959.4 & 620.4 & 730.3 \\
\hline
\end{tabular}

$\beta=-624 A^{2}-23.6 B^{2}+4686 A-628 B-1897$

$\gamma=-15.2 A^{2}+54.2 B^{2}+329 A-519 B+954$

The lower bound $\alpha, \beta$ and $\gamma$ are obtained by applying corrections $-108.66,-409.75$ and -69.2 to the results of Eqs. (3)-(5). Similarly, the upper bound $\alpha, \beta$ and $\gamma$ are obtained by applying corrections 73.97, 284.35 and 57.47 to the results of Eqs. (3)-(5). The test results in Table 6 are within the expected range using the developed empirical relations (3)-(5) for top bead width $(\alpha)$, depth of penetration $(\beta)$ and heat affected zone $(\gamma)$. Figures 2,3 and 4 show the variation of top bead width $(\alpha)$, depth of penetration $(\beta)$ and heat affected zone $(\gamma)$ with the laser power $(A)$ for the welding speed, $B=1 \mathrm{~m} / \mathrm{min}$.

In a truly quadratic model as being followed in the RSM (response surface methodology), cross-terms can be expected in the empirical relations while representing the output response in terms of input process variables.
It should be noted that empirical relations (3)-(5) are developed from the three mean values and corresponding level values of each input process parameter. Mean value plots of the output responses confirm the above quadratic relations. Equations (3)-(5) provide the results same as those obtained from the additive law [39] given in Eq. (2).

\subsection{Multi-objective optimization}

Multi-objective optimization can be performed easily to identify a set of optimum laser welding process parameters. To specify a unique set of laser welding process parameters, a simple and reliable multi-objective optimization procedure following the Taguchi approach is presented below. Since $\alpha$ and $\beta$ are two different output responses, they can be functionally represented after non-dimensioning them. For this purpose, the maximum values of $\alpha$ and $\beta$ evaluated from the ANOVA table 
Table 6 Estimates of the top bead width, $\alpha(\mu \mathrm{m})$, depth of penetration, $\beta(\mu \mathrm{m})$, and width of the heat affected zone, $\gamma(\mu \mathrm{m})$ from the developed empirical relations (3)-(5), and comparison with test data [22]

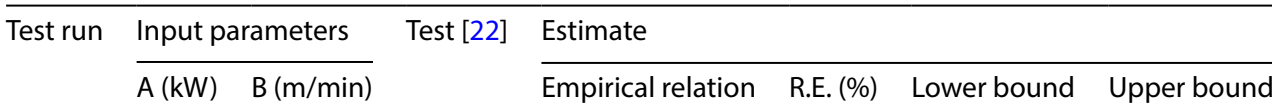

Top bead width, $\alpha(\mu \mathrm{m})$ using the empirical relation (3)

$\begin{array}{lllll}1 & 2.5 & 1 & 2156 & 2264.8 \\ 2 & 2.5 & 3 & 1480.9 & 1441.2 \\ 3 & 2.5 & 5 & 1310 & 1240 \\ 4 & 3 & 1 & 2367.2 & 2332.8 \\ 5 & 3 & 3 & 1493.2 & 1509.2 \\ 6 & 3 & 5 & 1290 & 1308 \\ 7 & 3.5 & 1 & 2730.3 & 2656.8 \\ 8 & 3.5 & 3 & 1810.3 & 1833.2 \\ 9 & 3.5 & 5 & 1581.3 & 1632\end{array}$

$\begin{array}{rll}-5.0 & 2156.2 & 2338.8 \\ 2.7 & 1332.6 & 1515.2 \\ 5.3 & 1131.4 & 1314 \\ 1.5 & 2224.2 & 2406.8 \\ -1.1 & 1400.6 & 1583.2 \\ -1.4 & 1199.4 & 1382 \\ 2.7 & 2548.2 & 2730.8 \\ -1.3 & 1724.6 & 1907.2 \\ -3.2 & 1523.4 & 1706\end{array}$

Depth of penetration, $\beta(\mu \mathrm{m})$ using the empirical relation (4)

$\begin{array}{lllll}1 & 2.5 & 1 & 5310 & 5266.4 \\ 2 & 2.5 & 3 & 3945.7 & 3821.6 \\ 3 & 2.5 & 5 & 2017.2 & 2188 \\ 4 & 3 & 1 & 6089.5 & 5893.4 \\ 5 & 3 & 3 & 4038.2 & 4448.6 \\ 6 & 3 & 5 & 3028.2 & 2815 \\ 7 & 3.5 & 1 & 5967.3 & 6208.4 \\ 8 & 3.5 & 3 & 5046.8 & 4763.6 \\ 9 & 3.5 & 5 & 3085.3 & 3130\end{array}$

Heat affected zone, $\gamma(\mu \mathrm{m})$ using the empirical relation (5)

\begin{tabular}{rllllrll}
1 & 2.5 & 1 & 1257.4 & 1216.7 & 3.2 & 1147.5 & 1274.2 \\
2 & 2.5 & 3 & 628.8 & 612.3 & 2.6 & 543.1 & 669.8 \\
3 & 2.5 & 5 & 382.4 & 441.5 & -15.5 & 372.3 & 499 \\
4 & 3 & 1 & 1287 & 1339.4 & -4.1 & 1270.2 & 1396.9 \\
5 & 3 & 3 & 786.4 & 735 & 6.5 & 665.8 & 792.5 \\
6 & 3 & 5 & 563.6 & 564.2 & -0.1 & 495 & 621.7 \\
7 & 3.5 & 1 & 1466.4 & 1454.5 & 0.8 & 1385.3 & 1512 \\
8 & 3.5 & 3 & 780.4 & 850.1 & -8.9 & 780.9 & 907.6 \\
9 & 3.5 & 5 & 735.8 & 679.3 & 7.7 & 610.1 & 736.8 \\
\hline
\end{tabular}

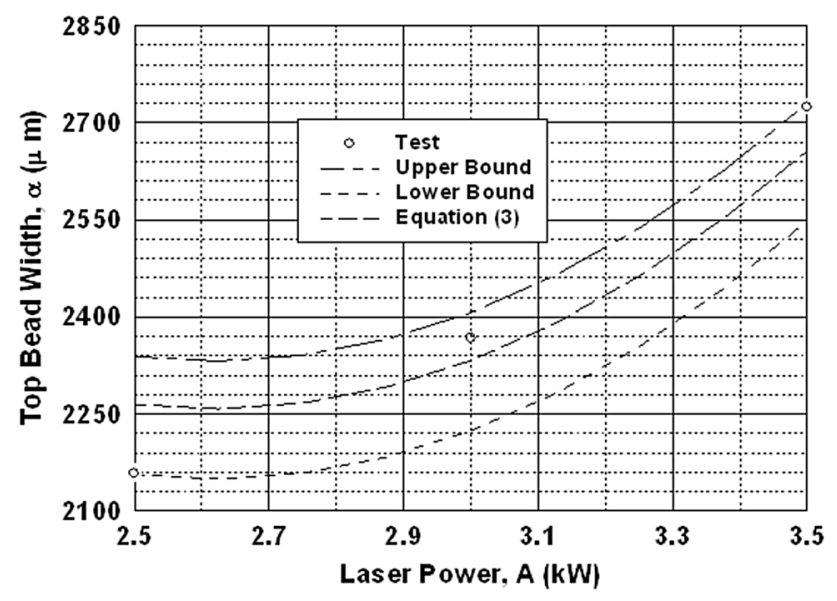

Fig. 2 Top bead width variation with laser power (welding speed, $\mathrm{B}=1 \mathrm{~m} / \mathrm{min}$ ) and comparison with test data [22]

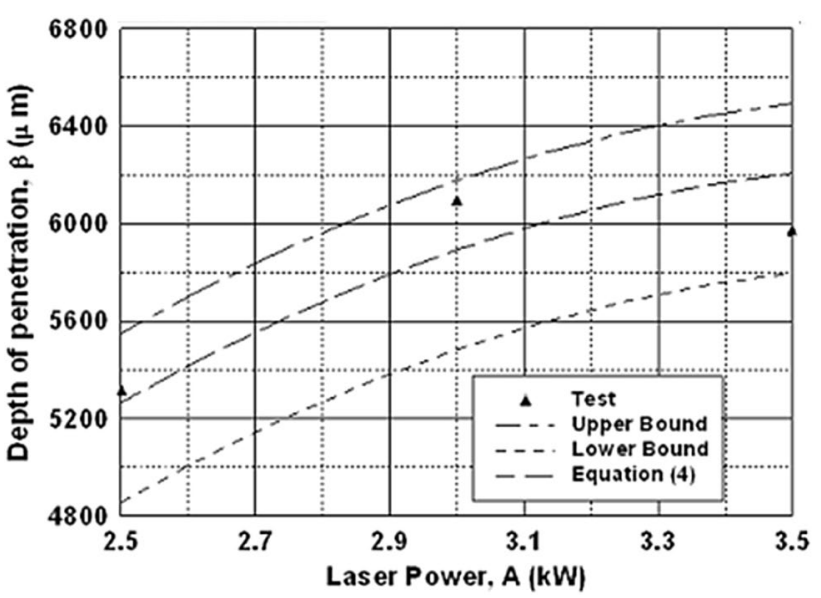

Fig. 3 Depth of penetration variation with laser power (welding speed, $B=1 \mathrm{~m} / \mathrm{min}$ ) and comparison with test data along with microstructures of laser BOP welds [22] 


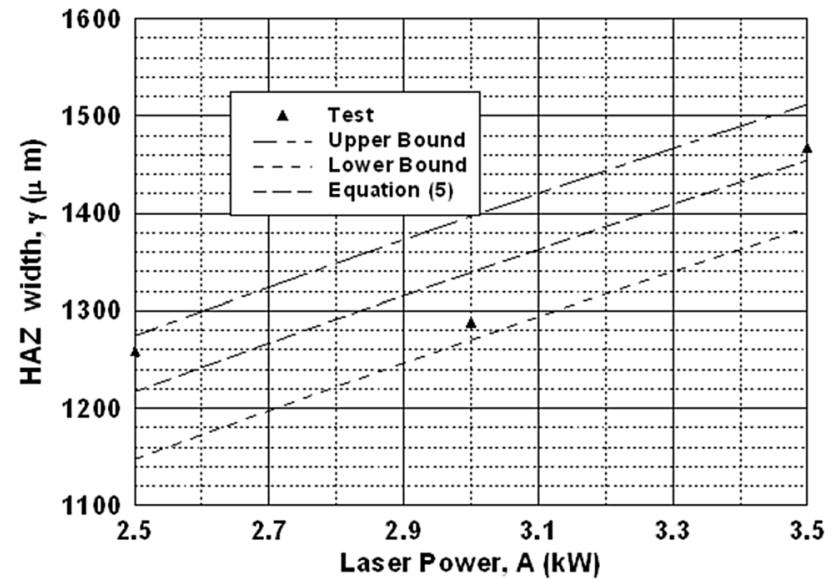

Fig. 4 Heat affected zone (HAZ) width variation with laser power (welding speed, $B=1 \mathrm{~m} / \mathrm{min}$ ) and comparison with test data [22]

considering the fictitious parameter are: $\alpha_{\max }=2730.3$ and $\beta_{\max }=6492.2$.

For optimum laser welding processing, one should expect minimum top bead width $(\alpha)$ and maximum depth of penetration $(\beta)$. It can be verified that $\zeta_{1}=\frac{\alpha}{\alpha_{\max }}$ and $\zeta_{2}=\left(\frac{\beta \max }{\beta}-1\right)$ will show monotonically decreasing or increasing trend. Defining the positive weighing factors $\omega_{1}$ and $\omega_{2}$ (such that $\omega_{1}+\omega_{2}=1$ ), one can define a single function ( $\zeta$ ) for the optimization of both responses (viz., $\alpha$ and $\beta$ ) as given by Eq. (6) $\zeta=\omega_{1} \zeta_{1}+\omega_{2} \zeta_{2}$

Minimization of $\zeta$ provides the minimum $\alpha$ and maximum $\beta$ for a set of welding input parameters on the specification of $\omega_{1}$ and $\omega_{2}$. It should be noted that for the specified $\omega_{1}=1$ (implies $\omega_{2}=0$ ), minimization of $\zeta$ yields mimimum $\alpha$ value. For the specified $\omega_{2}=1$ (implies $\omega_{1}=0$ ), minimization of $\zeta$ yields the maximum $\beta$ value. To achieve common optimum process conditions, equal weighing are given (i.e., $\omega_{1}=\omega_{2}=1 / 2$ ). Table 7 gives the values of $\zeta$ generated from Eq. (6) for each test run. ANOVA is performed on values of the multi-objective optimization function, $\zeta$ in Table 7 to trace the optimum process parameters for the minimum $\zeta$ and selected the optimal process parameters as $A_{2} B_{1} C_{1}$. The expected range of output responses for the optimum laser welding process parameters from Eq. (2) with inclusion of fictitious parameter are $\alpha \in$ [2223.8, 2314.1]; $\beta \in[5937.7,6177.7]$ and $\gamma \in[1270.2,1380]$. Table 8 provides laser welding process parameters for specific conditions and estimates of output responses. For minimum $\alpha$ and maximum $\beta$, the optimal process parameters are $\mathrm{A}_{2} \mathrm{~B}_{1} \mathrm{C}_{1}$.

It should be noted that for two significant laser welding process parameters (viz., laser power (A) and welding speed (B)) in the present study, full factorial experiments demand only $9\left(=3^{2}\right)$ test runs. The optimum process parameters can be easily obtained from the minimum $\zeta$ in Table 7 . Laser welding process parameters selected for minimum value of $\zeta$ from Table 7 are $A_{2} B_{1}$ (Test Run-4). The optimum laser welding process parameters for $A_{2} B_{1}$ are: Laser

Table 7 Multi-objective optimization function, $\zeta$ weighing equally (i.e., $\omega_{1}=\omega_{2}=\frac{1}{2}$ ) for the output responses of Table 1 $\left(\alpha_{\max }=2730.3 \mu \mathrm{m} ; \beta_{\max }=6492.2 \mu \mathrm{m}\right)$

\begin{tabular}{|c|c|c|c|c|c|c|c|c|c|}
\hline \multirow[t]{2}{*}{ Test runs } & \multicolumn{3}{|c|}{ Levels of input parameters } & \multirow[t]{2}{*}{$\alpha(\mu \mathrm{m})$} & \multirow[t]{2}{*}{$\zeta_{1}=\frac{\alpha}{\alpha_{\max }}$} & \multirow[t]{2}{*}{$\beta(\mu \mathrm{m})$} & \multirow{2}{*}{\multicolumn{2}{|c|}{$\zeta_{2}=\left(\frac{\beta \max }{\beta}-1\right)$}} & \multirow[t]{2}{*}{$\zeta$ Eq. (6) } \\
\hline & A & $\mathrm{B}$ & $\mathrm{C}$ & & & & & & \\
\hline 1 & 1 & 1 & 1 & 2156 & 0.7897 & 5310 & 0.2226 & & 0.5061 \\
\hline 2 & 1 & 2 & 2 & 1480.9 & 0.5424 & 3945.7 & 0.6454 & & 0.5939 \\
\hline 3 & 1 & 3 & 3 & 1310 & 0.4798 & 2017.2 & 2.2184 & & 1.3491 \\
\hline 4 & 2 & 1 & 2 & 2367.2 & 0.867 & 6089.5 & 0.0661 & & 0.4666 \\
\hline 5 & 2 & 2 & 3 & 1493.2 & 0.5469 & 4038.2 & 0.6077 & & 0.5773 \\
\hline 6 & 2 & 3 & 1 & 1290 & 0.4725 & 3028.2 & 1.1439 & & 0.8082 \\
\hline 7 & 3 & 1 & 3 & 2730.3 & 1 & 5967.3 & 0.088 & & 0.5440 \\
\hline 8 & 3 & 2 & 1 & 1810.3 & 0.663 & 5046.8 & 0.2864 & & 0.4747 \\
\hline 9 & 3 & 3 & 2 & 1581.3 & 0.5792 & 3085.3 & 1.1042 & & 0.8417 \\
\hline Parameters & & 1-Mean & & 2-Mean & 3-Mean & & squares & & ntribution \\
\hline \multicolumn{10}{|c|}{ ANOVA on the multi-objective optimization function, $\zeta$} \\
\hline A & & 0.81638 & & 0.61735 & 0.62013 & \multicolumn{2}{|c|}{0.07813} & & 12.1 \\
\hline B & & 0.50556 & & 0.54863 & 0.99966 & \multicolumn{2}{|c|}{0.44942} & & 69.7 \\
\hline C & & 0.59635 & & 0.63405 & 0.82346 & \multicolumn{2}{|c|}{0.08888} & & 13.8 \\
\hline
\end{tabular}

Bold indicates optimum value (i.e., the minimum value in the present case) of the multi-objective function corresponding to the identified levels of the input parameters 
Table 8 Laser welding process parameters for specific conditions and estimates of output responses

\begin{tabular}{|c|c|c|c|c|c|c|}
\hline \multirow[t]{2}{*}{ Specific conditions } & \multicolumn{3}{|c|}{ Laser welding input process parameters } & \multicolumn{3}{|c|}{ Expected range of output responses $(\mu \mathrm{m})$} \\
\hline & Power, A (kW) & $\begin{array}{l}\text { Speed, B } \\
\text { (m/min) }\end{array}$ & Focus, C (mm) & Top bead width $(\alpha)$ & Depth of penetration $(\beta)$ & Heat affected zone $(\gamma)$ \\
\hline \multicolumn{7}{|c|}{ Single objective optimization } \\
\hline$\alpha_{\max } \mathrm{A}_{3} \mathrm{~B}_{1} \mathrm{C}_{3}$ & 3.5 & 1 & -4 & $2640-2730(2730.3)^{\mathrm{a}}$ & $5798-6038(5967.3)$ & $1398-1507(1466.4)$ \\
\hline$\alpha_{\min } \mathrm{A}_{1} \mathrm{~B}_{3} \mathrm{C}_{1}$ & 2.5 & 5 & 0 & $1131-1222$ & $2231-2471$ & $371-481$ \\
\hline$\beta_{\max } \mathrm{A}_{3} \mathrm{~B}_{1} \mathrm{C}_{1}$ & 3.5 & 1 & 0 & $2548-2638$ & $6252-6492$ & $1386-1495$ \\
\hline$\beta_{\min } \mathrm{A}_{1} \mathrm{~B}_{3} \mathrm{C}_{3}$ & 2.5 & 5 & -4 & $1224-1315(1310)$ & $1777-2017(2017.2)$ & $382-492(382.4)$ \\
\hline$\gamma_{\max } A_{3} B_{1} C_{2}$ & 3.5 & 1 & -2 & $2605-2696$ & $6164-6404$ & $1402-1512$ \\
\hline$\gamma_{\min } A_{1} B_{3} C_{1}$ & 2.5 & 5 & 0 & $1132-1222$ & $2231-2471$ & $371-481$ \\
\hline \multicolumn{7}{|c|}{ Multi-objective optimization: $\alpha_{\min }$ and $\beta_{\max }$} \\
\hline$A_{2} B_{1} C_{1}$ & 3 & 1 & 0 & $2224-2314$ & $5938-6178$ & $1270-1380$ \\
\hline$A_{3} B_{1} C_{1}$ & 3.5 & 1 & 0 & $2548-2638$ & $6252-6492$ & $1386-1495$ \\
\hline
\end{tabular}

${ }^{\mathrm{a}}$ Test data [22]

power $=3 \mathrm{~kW}$ and welding speed $=1 \mathrm{~m} / \mathrm{min}$. The expected range of output responses for the optimum laser welding process parameters from Table 6 are: $\alpha \in[2224.2,2406.8]$; $\beta \in[5483.6,6177.7]$ and $\gamma \in[1270.2,1396.9]$. Confirmation experiments performed in [22] for laser power, $A=3 \mathrm{~kW}$, welding speed, $B=1 \mathrm{~m} / \mathrm{min}$ and focal position, $C=-4 \mathrm{~mm}$ yield the output responses: top bead width, $\alpha=2314.1 \mu \mathrm{m}$; depth of penetration, $\beta=6107.3 \mu \mathrm{m}$; and heat affected zone (HAZ) width, $\gamma=1132.4 \mu \mathrm{m}$. Test results of $\alpha$ and $\beta$ values are within the expected range, whereas test result of $\gamma$ value is close to the expected range.

The dissimilar quality characteristics of multiple responses in the present study are the top bead width and the depth of penetration, which are converted into a single response characteristic [see Eq. (6)] after nondimensioning them. This single response characteristic is used to trace the optimum process parameters adopting the Taguchi approach. The expected range of optimum output responses are validated with confirmation tests [22] for the identified set of input process variables.

The results of microstructure and micro-hardness tests [22], which confirm the optimum input process parameters (i.e. power $3 \mathrm{~kW}$ and speed $1 \mathrm{~m} / \mathrm{min}$ ) for the weld joint are as follows. The microstructure is uniform with the average grain size of $25 \mu \mathrm{m}$ in the base metal, $18 \mu \mathrm{m}$ in the weld and $15 \mu \mathrm{m}$ in the $\mathrm{HAZ}$, whereas the micro-hardness reported values are $270-320 \mathrm{HV} 0.2$ in welds and $240-265 \mathrm{HV} 0.2$ in HAZ against 220-240HV0.2 in the base metal.

\section{Concluding remarks}

High strength as well as structural stability and good corrosion/oxidation resistance of materials are suitable for the most exposed parts of steam power plants such as turbines, boilers and steam piping. P92 steel having such material characteristics is being used in power plant systems for high temperature applications. Present work deals with the identification of laser welding process parameters to achieve maximum depth of penetration and minimum weld width of P92 steel adopting the modified Taguchi approach. ANOVA analysis is performed to determine the significance of the laser welding processing parameters, viz. Laser power, welding speed and focal position on the output responses (viz., weld width, depth of penetration and width of heat affected zone (HAZ)). One of the process parameters, viz. the focal position is found to negligible variation on the overall mean value of the output responses. Following the concepts of the Taguchi method, the process designer can opt for any one of the set levels of the focal position during laser welding operation. Estimates of output responses with inclusion of fictitious parameter (D) are close to test results. From the ANOVA analysis results, the developed empirical relations for the output responses in terms of significant laser welding process parameters are reasonably in good agreement with test results. In tracing the optimal input process parameters, the dissimilar quality characteristics of multiple responses are represented by a single response characteristic (after non-dimensioning them) and utilized the Taguchi approach. This approach is quite simple, straight forward and reliable.

Acknowledgements The authors would like to thank the reviewers for their constructive criticisms and valuable suggestions to improve the quality of presentation.

\section{Compliance with ethical standards}

Conflict of interest On behalf of all authors, the corresponding author states that there is no conflict of interest. 


\section{References}

1. Ennis PJ, Filemonowicz AC (2003) Recent advances in creepresistant steels for power plant applications. Sadhana 28(3-4):709-730

2. Hu Z-F (2011) Heat resistant steels, microstructure evolution and life assessment in power plants. In: Rasul M (ed) Thermal power plants. InTech, Rijeka, pp 195-226

3. Vijayan V, Senthil Kumar T, Saravanan C, Kumaragurubaran B (2016) Indentation of creep testing on P92 material. Int J Adv Multidiscip Res (IJAMR) 3(6):68-74

4. Zhang J, Du BSh, Li XM, Qin GL, Zou Y (2017) Microstructure evolution of P92 steel weld metal after service for $8000 \mathrm{~h}$. Kovove Mater Met Mater 55:115-121. https://doi.org/10.4149/ km_2017_2_115

5. Pandey C, Mahapatra MM, Kumar P, Thakare JG (2018) Characterization of weld fusion zone for TIG welded P91 and P92 steels. Arch Metall Mater 63(4):1755-1761. https://doi.org/10.24425/ amm.2018.125102

6. Mohyla P, Havelka L, Kouril K (2018) Mechanical properties testing of P92 welded joints prepared by manual metal arc welding. Tech Gaz 25(1):60-63. https://doi.org/10.17559/TV-2016022414 1159

7. Lee WH, Shiue RK, Chen C (2003) Mechanical properties of modified $9 \mathrm{Cr}-1$ Mo steel welds with notches. Mater Sci Eng, A 356:153-161

8. Shanmugarajan B, Padmanabham G, Kumar H, Albert SK, Bhaduri AK (2011) Autogenous laser welding investigations on modified 9Cr-1Mo (P91) steel. Sci Technol Weld Join 16:528-534

9. Ross PJ (1989) Taguchi techniques for quality engineering. McGraw-Hill, Singapore

10. Srinivasa Rao B, Rudramoorthy P, Srinivas S, Nageswara Rao B (2008) Effect of drilling induced damage on notched tensile strength and pin-bearing strength of woven GFR-epoxy composites. Mater Sci Eng, A 472:347-352. https://doi.org/10.1016/j. msea.2007.03.023

11. Singaravelu J, Jeyakumar D, Nageswara Rao B (2009) Taguchi's approach for reliability and safety assessments in the stage separation process of a multistage launch vehicle. Reliab Eng Syst Saf 94(10):1526-1541. https://doi.org/10.1016/j. ress.2009.02.017

12. Parameshwaran Pillai T, Lakshminarayanan PR, Nageswara Rao B (2011) Taguchi's approach to examine the effect of drilling induced damage on the notched tensile strength of woven GFRepoxy composite. Adv Compos Mater 20:261-275. https://doi. org/10.1163/092430410X547083

13. Singaravelu J, Jeyakumar D, Nageswara Rao B (2012) Reliability and safety assessments on satellite separation process of a typical launch vehicle. J Defense Model Simul 9(4):369-382. https:// doi.org/10.1177/1548512911401939

14. Sahiti M, Raghavendra Reddy M, Joshi B, Peter Praveen J, Nageswara Rao B (2016) Optimum WEDM process parameters of Incoloy Alloy 800 using Taguchi method. Int J Ind Manuf Syst Eng 1(3):64-68. https://doi.org/10.11648/j.ijimse.20160103.14

15. Bharathi P, Priyanka TGL, Srinivasa Rao G, Nageswara Rao B (2016) Optimum WEDM process parameters of SS304 using Taguchi method. Int J Ind Manuf Syst Eng 1(3):69-72. https:// doi.org/10.11648/j.ijimse.20160103.15

16. Rajeev Kumar D, Varma PSSK, Nageswara Rao B (2017) Optimum drilling parameters of coir fiber-reinforced polyester composites. Am J Mech Ind Eng 2(2):92-97. https://doi. org/10.11648/j.ajmie.20170202.15

17. Konduri SSS, Kalavala VMK, Mandala P, Manapragada RR, Nageswara Rao B (2017) Application of Taguchi approach to seek optimum drilling parameters for woven fabric carbon fibre/ epoxy laminates. MAYFEB J Mech Eng 1:29-37

18. Dutta OY, Nageswara Rao B (2018) Investigations on the performance of chevron type plate heat exchangers. Heat Mass Transf 54(1):227-239. https://doi.org/10.1007/s0023 1-017-2107-3

19. Satyanarayana G, Narayana KL, Nageswara Rao B (2018) Identification of optimum laser beam welding process parameters for E1 10 zirconium alloy butt joint based on Taguchi-CFD simulations. Lasers Manuf Mater Process 5(2):182-193. https://doi. org/10.1007/s40516-018-0061-7

20. Rajyalakshmi K, Nageswara Rao B (2018) Expected range of the output response for the optimum input parameters utilizing the modified Taguchi approach. Multidiscip Model Mater Struct. https://doi.org/10.1108/MMMS-05-2018-0088

21. Rajyalakshmi K, Nageswara Rao B (2019) Modified Taguchi approach to trace the optimum GMAW process parameters on weld dilution for ST-37 steel plates. ASTM Int J Test Eval 47(4):3209-3223. https://doi.org/10.1520/JTE20180617

22. Shanmugarajan B, Shrivastava R, Sathiya P, Buvanashekaran G (2016) Optimization of laser welding parameters for welding of P92 material using Taguchi based grey relational analysis. Def Technol 12:343-350. https://doi.org/10.1016/j.dt.2016.04.001

23. Ribeiro J, Lopes H, Queijo L, Figueiredo D (2017) Optimization of cutting parameters to minimize the surface roughness in the end milling process using the Taguchi method. Period Polytech Mech Eng 61(1):30-35

24. Ribeiro JE, Cesar MB, Lopes H (2017) Optimization of machining parameters to improve the surface quality. Procedia Struct Integr 5:355-362

25. Jaiganesh V, Yokesh Kumar B, Sevvel P, Balaji AJ (2018) Optimization of process parameters on commercial mild steel using Taguchi technique. Int J Eng Technol 7(11):138-142

26. Bhirudi NL, Gawande RR (2017) Optimization of process parameters during end milling and prediction of work piece temperature rise. Arch Mech Eng 64(3):327-346. https://doi.org/10.1515/ meceng-2017-0020

27. Sonowal D, Sarma D, Barua PB, Nath T (2017) Taguchi optimization of cutting parameters in turning AISI 1020 MS with M2 HSS tool. In: IOP conference series: materials science and engineering, vol 225, p 012186. https://doi.org/10.1088/1757899x/225/1/012186

28. Cui F, Su Y, Xu S, Liu F, Yao G (2018) Optimization of the physical and mechanical properties of a spline surface fabricated by high-speed cold roll beating based on Taguchi theory. Math Probl Eng 2018, 8068362. https://doi.org/10.1155/2018/80683 62

29. Rama Rao S, Padmanabhan G (2015) Parametric optimization in electrochemical machining using utility based Taguchi method. J Eng Sci Technol 10(1):81-96

30. Kus A, Motorcu AR, Ekici E (2016) Wire electrical discharge machining of a hybrid composite: evaluation of kerf width and surface roughness. Uludağ Univ J Fac Eng 21(1):243-257. https ://doi.org/10.17482/uujfe.21303

31. Vinoth Kumar D, Siva Kumar P, Kumaragurubharan B, Senthil Kumar T (2016) Experimental investigation of process parameters in EDM for Incoloy 600 using Taguchi-GRA. Int J Eng Sci Comput 6(5):6202-6206

32. Singh H, Goyal K, Kumar P (2013) Experimental investigation of WEDM variables on surface roughness of AISI H13. Manuf Sci Technol 1(2):23-30

33. Banu A, Bakar MA, Ali MY, Adesta EYT (2017) Analysis of WEDM process parameters on surface roughness and kerf using Taguchi method. Int J Eng Mater Manuf 2(4):103-109 
34. Nourbaksh F, Rajukar KP, Malshe AP, Cao J (2013) “Wire electrodischarge machining of titanium alloy. Procedia CIRP 5:13-18

35. Laxman J, Guru Raj K (2014) Optimization of electric discharge machining process parameters using Taguchi technique. Int J Adv Mech Eng 4(7):729-739

36. Saxena V, Parvez MS (2015) Optimization of MIG welding parameters on tensile strength of aluminium alloy by Taguchi approach. Int J Eng Sci Res Technol 49(6):451-457

37. Devaiah D, Kishore K, Laxminarayana P (2016) Optimization of process parameters in friction stir welding of dissimilar aluminium alloys (AA5083 and AA6061) using Taguchi technique. Innov Res Sci Eng Technol (IJIRSET) 5(8):15303-15310

38. Kumar A, Sharma VK, Singh J (2015) Optimization of friction stir welding parameters for joining aluminum alloy 6105 using Taguchi technique. Int J Res Eng Technol (IJRET) 4(7):185-189

39. Rajeesh J, Balamurugan R, Balachandar K (2018) Process parameter optimization of friction stir welding of aluminium 2014-T651 alloy using Taguchi technique. J Eng Sci Technol 13(2):515-523

40. Kuram E, Ozcelik B (2013) Multi-objective optimization using Taguchi based grey relational analysis for micro-milling of $\mathrm{Al}$ 7075 material with ball nose end mill. Measurement 46(6):18491864. https://doi.org/10.1016/j.measurement.2013.02.002

41. Raykar SJ, Addona DMD, Mane AM (2015) Multi-objective optimization of high speed turning of Al 7075 using grey relational analysis. Procedia CIRP 33:293-298. https://doi.org/10.1016/j. procir.2015.06.052

42. Lal S, Kumar S, Khan ZA, Siddiquee AN (2015) Multi-response optimization of wire electrical discharge machining process parameters for $\mathrm{Al} 7075 / \mathrm{Al}_{2} \mathrm{O}_{3} / \mathrm{SiC}$ hybrid composite using Taguchi-based grey relational analysis. Proc IMechE Part B J Eng Manuf 229:229-237. https://doi.org/10.1177/0954405414 526382

43. Puh F, Jurkovic Z, Perinic M, Brezocnik M, Buljan S (2016) Optimization of machining parameters for turning operation with multiple quality characteristics using Grey relational analysis. Tehnički Vjesnik 23(2):377-382. https://doi.org/10.17559/ TV-20150526131717
44. Kasemsiri P, Dulsang N, Pongsa U, Hiziroglu S (2017) Chindaprasirt $P$ (2017) Optimization of biodegradable foam composites from cassava starch, oil palm fiber, chitosan and palm oil using Taguchi method and grey relational analysis. J Polym Environ 25:378-390

45. Sylajakumari PA, Ramakrishnasamy R, Palaniappan G (2018) Taguchi grey relational analysis for multi-response optimization of wear in co-continuous composite. Materials 11:1743. https:// doi.org/10.3390/ma11091743

46. Sonawane NK, Khalkar MY, Shinde VB (2016) A review on parameters optimization in abrasive water jet cutting. Int $\mathrm{J}$ Innov Emerg Res Eng 3(2):11-14

47. Jain NK, Jain VK, Deb K (2007) Optimization of process parameters of mechanical type advanced machining processes using genetic algorithms. Int J Mach Tools Manuf 47:900-919

48. Zain AM, Haron H, Sharif S (2011) Optimization of process parameters in the abrasive water jet machining using integrated SA-GA. Appl Soft Comput 11:5350-5359

49. Venkata Rao R, Kalyankar VD (2013) Parameter optimization of modern machining processes using teaching-learning-based optimization algorithm. Eng Appl Artif Intell 26:524-531

50. Liu D, Huang C, Wang J, Zhu H, Yao P, Liu ZW (2014) Modelling and optimization of operating parameters for abrasive water jet turning alumina ceramics using response surface methodology combined with Box-Behnken design. Ceram Int 40:7899-7908

51. Aich U, Banerjee S, Bandyopadhyay A, Das PK (2014) Abrasive water jet cutting of borosilicate glass. Procedia Mater Sci 6:775-785

Publisher's Note Springer Nature remains neutral with regard to jurisdictional claims in published maps and institutional affiliations. 